\title{
A GESTÃO COLETIVA DOS DIREITOS AUTORAIS E O STREAMING
}

\author{
Marcos Wachowicz ${ }^{1}$ \\ Universidade Federal do Paraná - UFPR \\ marcos.wachowicz@gmail.com \\ Bibiana Biscaia Virtuoso ${ }^{2}$ \\ Universidade Federal do Paraná - UFPR \\ bibianavirtuoso@gmail.com
}

\begin{abstract}
Resumo
O presente artigo analisa a tecnologia utilizada no modelo de distribuição de música e audiovisual por meio de streaming, abordando as questões jurídicas e polemicas do licenciamento e remuneração dos autores e produtores de conteúdos na INTERNET. O conceito de execução pública para legitimar a gestão de Direitos Autorais pelo ECAD nos serviços de streaming tem sido objeto de controvérsias, inobstante o entendimento dado pela justiça brasileira, que acarreta numa dupla camada de remuneração retendo altos ganhos que viriam a ser dos artistas e produtores de conteúdo. A pesquisa permite concluir que a respeito da tecnologia streaming e a gestão de direitos autorais deve ser pensada a nível global para uma justa remuneração dos autores.
\end{abstract}

Palavras-chave: Gestão Coletiva de Direitos Autorais - Streaming.

\section{CROWD MANAGEMENT OF COPYRIGHT AND STREAMING}

\begin{abstract}
The present article analyses the technology employed in the streaming distribution model of music and audiovisual content, addressing legal matters and controversies of the licensing and payment of authors and content producers in the internet. The concept of public execution to legitimize the collective management of Copyright by ECAD in streaming services has been object of controversy, regardless of the understanding of Brazilian justice, which results in a "second layer" of money collection that retains a great amount of profit which would have been destined to artists and content producers. The research concludes that the streaming technology and the collective management of Copyright must be discussed in a global level to ensure a fair payment to authors.
\end{abstract}

Key words: Collective management of Copyright - Streaming.

\footnotetext{
${ }^{1}$ Doutor em Direito pela Universidade Federal do Paraná - UFPR. Mestre em Direito pela Universidade Clássica de Lisboa - Portugal. Atualmente é professor de Direito da Propriedade Intelectual na Universidade Federal do Paraná - UFPR. Coordenador do Grupo de Estudos de Direito Autoral e Industrial - GEDAI vinculado ao Programa de Pós-Graduação em Direito da UFPR.

${ }^{2}$ Pesquisadora do Grupo de Estudos de Direito Autoral e Industrial - GEDAI vinculado ao Programa de Pós-Graduação em Direito da UFPR. Advogada especializada em Propriedade Intelectual.
}

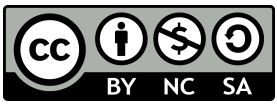

P2P \& INOVAÇÃO, Rio de Janeiro, v. 4 n. 1 p.4-17, Set./ Fev. 2018. 


\section{STREAMING SUA TECNOLOGIA E MODALIDADES}

A princípio para se analisar o conceito de streaming, deve-se conhecer os seus aspectos técnicos subjacentes ao novo modelo de negócios de distribuição de música e áudio visuais pela Internet.

O streaming é tecnologia que realiza uma distribuição online de pacotes de dados que surgiu em 2006, mas que somente nos últimos quatro anos teve seu uso massificado na Internet, a tal ponto de que o download, passa a ser deixado de lado, para dar espaço ao serviço de streaming que permite uma maior interatividade, possibilitando a criação de playlists, não sendo mais necessário possuir memória no computador ou celular: basta o acesso a internet e um login e senha.

O streaming se divide em duas modalidades: não interativo e interativo (on demand).

O Streaming não interativo é aquele em que a interatividade quase não existe. É o modelo que se aproxima muito das rádios tradicionais. Aqui o usuário não possui liberdade de escolha do que deseja ouvir ou ver. Nesta modalidade que se encontra o chamado simulcasting, espécie de rádio online que reproduz, simultaneamente, um programa via radiofusão.

A segunda modalidade diz respeito ao streaming interativo, também chamado de streaming on demand. Nesta modalidade, o usuário pode iniciar a transmissão da obra quando desejar, como se dispusesse do fonograma. É onde se enquadra o chamado webcasting. Também é a modalidade que se enquadram as principais plataformas de streaming.

O streaming on demand surge como um novo agente intermediador na indústria fonográfica, funcionando ao mesmo tempo como tecnologia e loja. É nesta modalidade que surgem as maiores discussões acerca da tecnologia, no que toca a uma justa remuneração dos Direitos Autorais do conteúdo que está sendo transmitido em tais plataformas.

\section{O LICENCIAMENTE DAS OBRAS MUSICAIS NAS PLATAFORMAS}

A remuneração do serviço se baseia na parcela paga de usuários que possuem a assinatura. A maior parte da receita é utilizada para pagar o licenciamento das músicas e os custos da empresa. 
O valor das assinaturas é determinado pelas matrizes das empresas, de forma que ainda há uma dependência das gravadoras e dos acordos firmados ${ }^{3}$.

Muitas destas plataformas possuem a opção da assinatura gratuita. É o caso do Spotify ${ }^{4}$. Nestes casos as opções são mais restritas, tendo, por exemplo, um número limitado de vezes para trocar de música. É uma estratégia adotada pelas plataformas para demonstrar o produto e mostrar os benefícios da versão paga.

Outra limitação apresentada pelo modelo freemium $^{5}$ é a presença constante de propagandas. A publicidade serviria para cobrir os custos desta opção gratuita. É o que se denomina de modelo de flot: geração de renda por associação com a publicidade ${ }^{6}$. Contudo, os produtores de conteúdo discordam desta forma de remuneração, exigindo valores fixos, independente do número de usuários.

O licenciamento das obras musicais nas plataformas de streaming e a busca de uma justa remuneração dos autores e interpretes, ganhou visibilidade no polêmico caso da cantora Taylor Swift que foi muito criticada por ter retirado todos os seus álbuns do catálogo de um dos maiores serviços de streaming, o Spotify, em novembro de 2014. Coincidentemente, foi na mesma época em que seu álbum de maior sucesso, “1989”, foi lançado mundialmente.

Swift, que já possuía uma bem-sucedida carreira, foi recordista de público com a turnê do show “1989”, e ainda, o álbum físico vendeu mais 10 milhões de cópias e sendo que ela ainda vendeu mais de 100 milhões de singles apenas nos Estados Unidos.

Após o atingimento desta marca de vendagem expressiva de álbuns físicos em $08 \mathrm{de}$ junho de 2017, a cantora surpreende anunciar seu retorno aos serviços de streaming. Em um mês na plataforma, Swift chegou a quase 18 milhões de ouvintes e seis milhões de seguidores. A música mais tocada do álbum “1989" teve 83 milhões de streams, um fato grandioso, se tratando de uma canção lançada há quase três anos

Mas o que mudou? Seu retorno foi um presente aos seus fiéis fãs ou ela finalmente chegou a um acordo em relação aos contratos com as plataformas de streaming?

\footnotetext{
${ }^{3}$ FRANCISCO, Pedro Augusto P.; VALENTE, Mariana Giorgetti (Org.). Do rádio ao streaming: ECAD, Direito autoral e música no Brasil. Rio de Janeiro: Beco do Azougue, 2016. 390 p. p.280.

${ }^{4}$ Spotify é um serviço de música comercial em streaming, podcasts e vídeo comercial que fornece conteúdo provido de restrição de gestão de direitos digitais de gravadoras e empresas de mídia, incluindo a Universal Music, a Sony Music e a Warner Music.

${ }^{5}$ Freemium é um modelo de negócio em que um produto ou serviço proprietário (tipicamente uma oferta digital como software, mídia, jogos ou serviços web) é oferecido gratuitamente, mas dinheiro é cobrado a usuários premium por recursos adicionais, funcionalidade ou bens virtuais

${ }^{6}$ PESSERL, Alexandre Ricardo. Estudos comparados sobre Direitos Autorais no Ambiente Digital (Internet): Produto 04 - Soluções Implementadas por empresas. Brasília: Ministério da Cultura, 2014. p. 22.
} 
Os embates de Swift contra os serviços de streaming, principalmente o Spotify, deixam à mostra a insatisfação que alguns músicos possuem em relação a este tipo de plataforma.

O Spotify é a plataforma mais famosa. Em março de 2017, chegou a marca de 50 milhões de assinaturas ${ }^{7}$ pagas e os números só crescem.

Por que um serviço que se mantem em crescimento incomoda os artistas? Como garantir a justa remuneração dos cantores? Como o Brasil lida com esta tecnologia? E o direito autoral?

O serviço de streaming é uma nova modalidade de distribuição de conteúdo promovido por gravadoras e empresas de mídia, sendo necessário compreender como a gestão de direitos autorais se opera neste ambiente digital para proteção dos interesses dos autores e criadores e sua justa remuneração.

\section{A GESTÃo DE DIREITOS AUTORAIS NOS SERVIÇOS DE STREAMING}

Aos compositores, interpretes e produtores de obras áudio/visuais lhes são garantidos os direitos morais e patrimoniais relativamente a sua criação intelectual, já a quase 20 anos pela Lei n. 9.610/98.

Ressalte-se que, é na utilização da obra pelo público que lhes proporciona a remuneração à qual a proteção lhes dá direito. Para que isto ocorra, é necessária uma efetiva fiscalização a fim de que os direitos de autor não sejam violados. Originalmente, a gestão destes direitos é prerrogativa do titular e/ou autor da obra, conforme o artigo 98, da Lei 9.610/98. No entanto, devido a intensa veiculação da obra e a impossibilidade física de fiscalização, torna-se ineficaz a atuação por parte do próprio titular. ${ }^{8}$

Assim, com o intuito de resguardar e efetivar a autorização, o controle, a arrecadação e a distribuição dos direitos, os artistas têm a faculdade de reunirem-se em associações de gestão coletiva dos direitos autorais na utilização comercial de suas obras.

Contudo a rapidez da inserção no mercado dos serviços de streaming foi surpreendente, a ponto de que em janeiro de 2017, os DVDs e Blu-rays deixaram de ser o

\footnotetext{
${ }^{7}$ REUTERS. Spotify atinge 50 milhões de assinantes pagos: Serviço sueco de streaming de músicas aumenta em $25 \%$ a base de usuários pagantes em menos de seis meses. Disponível em: http://g1.globo.com/tecnologia/noticia/spotify-atinge-50milhoes-de-assinantes-pagos.ghtml. Publicado em 03 mar. 2017. Acesso em: 04 jul. 2017.

8 WACHOWICZ, Marcos. A GESTÃO COLETIVA DE DIREITOS AUTORAIS DA OBRA MUSICAL: titularidade originária, supervisão pública e transparência. In: SIMÃO, J.F.; BELTRÃO, S.R. Estudos em Homenagem a José de Oliveira Ascensão - Direito Civil: Estudos Em Homenagem A José De Oliveira Ascensão: Direito Privado. Editora: Atlas. Edição: $1^{\mathrm{a}} / 2015$, pg. 268.
} 
meio mais lucrativo para distribuição de mídia no Reino Unido, sendo ultrapassados pelo download digital e streaming. ${ }^{9}$

É preciso ter-se claro que somente a empresa Spotify possui mais de 30 milhões de obras em seu acervo ${ }^{10}$. É um número inimaginável de músicas, sequer pensando há 20 anos. Com um acervo tão imenso, é possível controlar a distribuição de direitos autorais das obras?

\subsection{OS MODELOS DE GESTÃO COLETIVA DE DIREITOS AUTORAIS}

O controle dos Direitos Autorais tradicionalmente é feito através das entidades de gestão coletiva, a qual é definida pela Organização Mundial de Propriedade Intelectual (OMPI), como o exercício de direito de autor e direitos conexos, por meio de organizações que agem no interesse e em nome dos titulares das obras ${ }^{11}$. Segundo a OMPI, há três modelos de gestão coletiva: o tradicional, o one-stop-shopse e o dos centros de compensação de direitos.

O primeiro é o modelo tradicional, no qual as entidades atuam em nome dos seus membros, negociando taxas, licenças e distribuindo royalties. Não há um envolvimento direto do titular no processo.

O segundo modelo é denominado de one-stop-shops. Funciona como uma junção das entidades de gestão coletiva, formando uma fonte centralizada e facilitando a obtenção de licenças. É o modelo adotado pela plataforma da Apple, o iTunes. No Brasil, quem realiza a intermediação é a UBEM (União Brasileira de Editoras de Música) ${ }^{12}$.

O último modelo diz respeito ao que se chama de centros de compensação de direitos (right clearance centers). Neste modelo, as licenças são concedidas aos usuários. Os centros de compensação atuam como um agente do titular dos direitos. Este, por sua vez, está diretamente envolvido na determinação dos termos de uso das suas próprias obras.

A gestão coletiva é uma espécie de atividade administrativa que possibilita aos detentores dos direitos autorais e conexos receberem pelo uso de suas obras. Estes detentores

\footnotetext{
${ }^{9}$ HIGA, Paulo. Nem a Sony esperava que a decadência dos DVDs e Blu-ray fosse tão rápida. A Sony Pictures sofre perdas de R 3 bilhões devido ao declínio da mídia física. Disponível em: https://tecnoblog.net/206492/sony-decadencia-dvd-bluray-perdas/ Publicado em: 27 jan. 2017. Acesso em: 20 jul.2017

${ }^{10}$ SILVA, Victor Hugo. Do catálogo ao consumo de dados: qual o melhor streaming de música?

Disponível em: http://tecnologia.ig.com.br/2016-03-24/do-catalogo-ao-consumo-de-dados-qual-o-melhor-streaming-demusica.html. Publicado em: 24 mar. 2016. Acesso em: 05 jul. 2017

${ }^{11}$ Word Intellectual Property Organization. Collective Management of Copyright and Related Rights. Disponível em: <http://www.wipo.int/copyright/en/management/>. Acesso em: 19 out. 2016. 6

${ }^{12}$ FRANCISCO, Pedro Augusto P.; VALENTE, Mariana Giorgetti (Org.). Do rádio ao streaming: ECAD, Direito autoral e música no Brasil. Rio de Janeiro: Beco do Azougue, 2016. 390 p. p.333
} 
se reúnem em associações que servem como mandatárias de diversos titulares de direitos autorais, podendo até mesmo recolher os valores devidos a título das obras.

A grande vantagem é a forma de reduzir os custos e de redistribuir os valores arrecadados, além de fiscalizar, uma vez que é muito difícil realizar um controle por conta própria de cada titular.

\subsection{O SISTEMA DE GESTÃO COLETIVA NO BRASIL}

No Brasil, a gestão coletiva é realizada na forma de um monopólio legal, com um único escritório sendo responsável pelos direitos advindos da execução pública: o ECAD (Escritório Central de Arrecadação e Distribuição). A gestão coletiva se encontra positivada na Lei de Direitos Autorais (Lei 9610/98, artigos 97 a 100) e regulamentada pelo Decreto $8.469 / 2015)$.

O ECAD é uma associação das associações de gestão coletiva, funcionando como um ente centralizador da arrecadação e distribuição dos direitos decorrentes da execução pública.

Este modelo é duramente criticado, pois seria um desperdício de recursos administrativos, o que diminuiria o ganho final do titular do direito. É o que se chama de “dupla camada". Para além do escritório central, outras associações ficam responsáveis pelo cadastro das obras e repasse dos valores ${ }^{13}$.

Ademais, é o ECAD quem define os preços a serem cobrados pelo uso da obra, considerando importância da música para o estabelecimento que a utiliza, a atividade exercida pelo usuário da obra, a periodicidade da sua utilização e a maneira como a apresentação se realiza ${ }^{14}$

Alguns autores, como Carlos Alberto Bittar, criticam esta cobrança, uma vez que não haveria um padrão mínimo ou máximo desta cobrança, o que deveria ser determinado a partir de lei ou por pactuação privada ${ }^{15}$.

O sistema de gestão coletiva também é criticado pela obrigatoriedade de associação. O professor José de Oliveira Ascenção afirma que estas limitações do controle das obras

\footnotetext{
${ }^{13}$ FRANCISCO, Pedro Augusto P.; VALENTE, Mariana Giorgetti (Org.). Do rádio ao streaming: ECAD, Direito autoral e música no Brasil. Rio de Janeiro: Beco do Azougue, 2016. 390 p. p.171

${ }^{14}$ ARENHART, Gabriela. Gestão Coletiva de Direitos Autorais e a Necessidade de Supervisão Estatal. Publicado em: 25 jul. 2014. Disponível em: http://www.gedai.com.br/?q=pt- br/content/gest\%C3\%A3o-coletiva-de-direitos-autorais-enecessidade-de-supervis\%C3\%A3o-estatal

${ }^{15}$ BITTAR, Carlos Alberto. Contornos atuais do Direito do Autor. São Paulo: Revista dos Tribunais, 1999.
} 
levariam a uma gestão coletiva necessária, obrigatória ${ }^{16}$. Criar-se-ia uma nova relação: autor - associação - usuário.

Outra crítica se dá na esfera da concessão das licenças. No Brasil, utiliza-se as chamadas blanket licenses (licenças em brancos). São licenças que não especificam quais obras são abrangidas nem quantas vezes elas serão executadas, somente cuidando do prazo para sua utilização. O problema é que este tipo de licença gera um prejuízo muito grande ao usuário, uma vez que ele dificilmente utilizará o repertório integralmente.

\section{O STREAMING E O CONCEITO DE EXECUÇÃO PÚBLICA}

Dentre os direitos que são abarcados pelas entidades de gestão coletiva, destaca-se o que se chama de direito de execução pública. No Brasil, é o direito que fundamenta o funcionamento do ECAD encontra-se positivado no artigo 68 da Lei de Direitos Autorais. ${ }^{17}$

O Direito de Execução Pública diz respeito às execuções de obras musicais ou literomusicais em locais de frequência coletiva ${ }^{18}$, entendida esta como sendo os locais que vão além da esfera individual, locais onde há um número considerável de pessoas. É a partir desta noção que se legitima a cobrança.

No Brasil, a discussão se dá em torno da possibilidade do ECAD realizar a cobrança, partindo do pressuposto do streaming como forma de execução pública.

\footnotetext{
${ }^{16}$ ASCENSÃO, José de Oliveira. Direito autoral. Rio de Janeiro: Renovar, 1997. p. 620

17 Art. 68. Sem prévia e expressa autorização do autor ou titular, não poderão ser utilizadas obras teatrais, composições musicais ou lítero-musicais e fonogramas, em representações e execuções públicas.

(...)

$\S 2^{\circ}$ Considera-se execução pública a utilização de composições musicais ou lítero-musicais, mediante a participação de artistas, remunerados ou não, ou a utilização de fonogramas e obras audiovisuais, em locais de frequência coletiva, por quaisquer processos, inclusive a radiodifusão ou transmissão por qualquer modalidade, e a exibição cinematográfica.

$\S 3^{\circ}$ Consideram-se locais de frequência coletiva os teatros, cinemas, salões de baile ou concertos, boates, bares, clubes ou associações de qualquer natureza, lojas, estabelecimentos comerciais e industriais, estádios, circos, feiras, restaurantes, hotéis, motéis, clínicas, hospitais, órgãos públicos da administração direta ou indireta, fundacionais e estatais, meios de transporte de passageiros terrestre, marítimo, fluvial ou aéreo, ou onde quer que se representem, executem ou transmitam obras literárias, artísticas ou científicas.

$\S 4^{\circ}$ Previamente à realização da execução pública, o empresário deverá apresentar ao escritório central, previsto no art. 99, a comprovação dos recolhimentos relativos aos direitos autorais.

$\S 5^{\circ}$ Quando a remuneração depender da frequência do público, poderá o empresário, por convênio com o escritório central, pagar o preço após a realização da execução pública.

$\S 6^{\circ} \mathrm{O}$ usuário entregará à entidade responsável pela arrecadação dos direitos relativos à execução ou exibição pública, imediatamente após o ato de comunicação ao público, relação completa das obras e fonogramas utilizados, e a tornará pública e de livre acesso, juntamente com os valores pagos, em seu sítio eletrônico ou, em não havendo este, no local da comunicação e em sua sede.

(...)

${ }^{18}$ FRANCISCO, Pedro Augusto P.; VALENTE, Mariana Giorgetti (Org.). Do rádio ao streaming: ECAD, Direito autoral e música no Brasil. Rio de Janeiro: Beco do Azougue, 2016. 390 p. p.139.
} 
O caso mais emblemático diz respeito à empresa de telefonia Oi. O ECAD intentava que a extinta Rádio Oi pagasse pela veiculação da programação da rádio tradicional na internet.

A partir deste caso, o Judiciário firmou o conceito de simulcasting e webcasting: (i) SIMULCASTING. Como sendo a transmissão simultânea difundida por meio de sinais convencionais, sendo vedado por ser o novo recolhimento uma dupla cobrança sobre o mesmo fato gerado (bis in idem), e; (ii) WEBCASTING. Entendido como uma tecnologia que possibilita o envio de informações através de pacotes de dados por Rede de Computadores, e, portanto, a execução de mídia em computador e distribuição digital de fonogramas ensejando um novo fato gerador que autoriza a cobrança de Direitos Autorais pela utilização de obra litero-musical. ${ }^{19}$

O acórdão referente à Apelação Cível nº 0174958.45.2009.8.19.000 define o conceito de execução pública como transmitir, comunicar ou colocar à disposição do público uma obra, através de qualquer meio ou processo e que os integrantes desse público recebem essa obra no mesmo lugar ou em locais separados, ao mesmo tempo ou tempos diferentes.

Como o streaming se trata verdadeiramente do chamado webcasting (modalidade interativa), dar-se-ia início a um novo fato gerador de cobrança dos direitos autorais, legitimando o ECAD para recolher estes valores.

Entretanto, em sede recursal, foi afastada a noção de webcasting como execução pública (recurso especial $\mathrm{n}^{\mathrm{o}}$ 1.559.264). Segundo o acórdão, embora o acervo musical esteja disponibilizado no site da rádio ao acesso público, resta evidente que uma vez selecionado pelo usuário o conteúdo que deseja ouvir, será iniciada uma transmissão individual e dedicada, cuja execução da obra musical será restrita apenas a localidade daquele usuário. A transmissão de música pela Internet na modalidade webcasting, tal como descrita na presente hipótese, não se configura como execução pública de obras musicais, nem em local de frequência coletiva" ${ }^{20}$.

Em 09 de novembro de 2016, o Ministro Marco Aurélio Bellizze afirmou que o pagamento em razão de execução pública implicaria em um bis in idem, de forma que apenas o simulcasting seria considerado para fim de cobrança pelo ECAD.

\footnotetext{
${ }^{19}$ BRASIL. Tribunal de Justiça do Estado do Rio de Janeiro. Apelação Cível $\mathbf{n}^{\circ}$ 0174958.45.2009.8.19.0001. Relator: Desembargador Antonio Saldanha Palheiro. Rio de Janeiro, RIO DE JANEIRO, 12 de abril de 2011.

${ }^{20}$ BRASIL. Tribunal de Justiça do Estado do Rio de Janeiro. Recurso Especial $\mathbf{n}^{\mathbf{0}}$ 1.559.264. Relator: Ministro Ricardo Villas Boas Cueva. RIO DE JANEIRO, 21 de outubro de 2015
} 
Contudo, em decisão datada em 15 de fevereiro de 2017, o Ministro Villas Bôas Cueva alterou o entendimento anterior, entendendo que a disponibilização das obras musicais por meio da tecnologia STREAMING. SIMULCASTING E WEBCASTING, configura execução pública sendo um novo fato gerador cuja tabela de preços é fixada pelo ECAD. Apontando ainda que, é irrelevante a quantidade de pessoas que se encontram no ambiente de execução musical para a configuração de um local como de frequência coletiva. Relevante, assim, é a colocação das obras ao alcance de uma coletividade frequentadora do ambiente digital, que poderá, a qualquer momento, acessar o acervo ali disponibilizado. Logo, o que caracteriza a execução pública de obra musical pela internet é a sua disponibilização decorrente da transmissão em si considerada, tendo em vista o potencial alcance de número indeterminado de pessoas. ${ }^{21}$

Segundo a decisão, o que importa é a colocação das obras ao alcance de uma coletividade frequentadora do ambiente digital, que poderá a qualquer momento acessar o acervo ali disponibilizado.

O que caracteriza a execução pública no ambiente digital seria sua disponibilização decorrente da transmissão em si considerada, tendo em vista o potencial alcance de número indeterminado de pessoas.

As plataformas digitais permitem um alcance indeterminado e irrestrito de usuários, em todos os cantos do mundo, elevando exponencialmente a capacidade de exploração econômica das obras.

A sociedade informacional abre uma nova noção do que é público. Hoje, o simples fato de a obra intelectual estar à disposição, ao alcance do público, no ambiente coletivo da internet, por si só, é capaz de tornar a execução musical pública.

A autorização de cobrança de direitos autorais pelo ECAD nas transmissões via streaming não se dá em decorrência do ato praticado pelo indivíduo que acessa o site, mas, sim, pelo ato do provedor que o mantém, disponibilizando a todos, ou seja, ao público em geral, o acesso ao conteúdo.

Assim, tanto o simulcasting quanto o webcasting caracterizariam execução pública.

Neste ponto, importante se falar em um novo direito, chamado de direito de colocação à disposição do público, conhecido também por making available. É um direito surgido na metade dos anos 90, a fim de orientar a legislação sobre direitos autorais no ambiente digital, uma verdadeira solução geral.

${ }^{21}$ BRASIL. Superior Tribunal de Justiça. Recurso Especial no 1.559.264. Brasília, DF, 15 de fevereiro de 2017. 
Trata-se do direito de autorizar a disponibilização para o público, por qualquer meio, a fim de que o ouvinte possa acessar o fonograma quando e onde desejar.

No Brasil, este conceito se encontra positivado no artigo 29, VII da Lei de Direito Autoral. É uma nova noção que traz a ideia da distribuição, o que ocorre no webcasting e streaming on demand.

A partir da decisão proferida pelo STJ, o direito de colocação à disposição do público acabaria se caracterizando como forma de execução pública e, portanto, legitimando a cobrança pelo ECAD.

Para além das discussões acerca de ser o serviço de streaming uma execução pública ou da parte dos artistas em não concordam com os termos estabelecidos pelas plataformas de streaming, há outras questões polemicas que também devem ser consideradas, a saber:

A) Alto custo estrutural. É necessário um número muito grande de usuários para que o negócio seja rentável. Isso acaba gerando uma dependência ainda maior das plataformas com os detentores de conteúdo.

B) Conectividade. É absolutamente necessário que a conectividade com a internet seja veloz para que o serviço funcione de forma adequada. Em países como o Brasil, a conexão com a internet é extremamente lenta, o que prejudica na hora de recebimento do sinal e dos dados, diminuindo a qualidade das músicas e filmes.

C) Transparência. É necessário destacar a pouca transparência das plataformas no que tange a distribuição dos direitos autorais. São informações difíceis de serem encontradas, as quais raramente chegam aos usuários e artistas. São valores determinados pelas gravadoras, com pouca participação de quem produziu a obra.

Dentre as três principais plataformas de streaming musical, o Spotify divulgou que paga uma média por reprodução entre 0,006 e 0,0084 dólares, ou pouco mais de 0,005 e 0,0074 euros. A Apple Music paga cerca de 0,005\$ por reprodução, segundo dados que chegaram à Digital Music News ${ }^{22}$. O Tidal, plataforma fundada especificamente com o objetivo de aumentar os ganhos para os músicos, também mantém segredo relativamente às porcentagens pagas aos artistas e ao valor médio de uma reprodução de uma canção. Valores não oficiais divulgados pela Digital Music News apontam para uma média de cerca de 0,01\$ por reprodução 23 .

\footnotetext{
${ }^{22}$ SILVA, Marta Santos. Ouvir uma canção no Spotify vale 0,005€. Mas isso é muito ou pouco?. 2016. Disponível em: <https://eco.pt/2016/11/13/ouvir-uma-cancao-no-spotify-vale-0005e-mas-isso-e- muito-ou-pouco/>.

${ }^{23}$ Valores apurados no primeiro semestre de 2016.
} 
Frisa-se que estes valores são todos aproximados, uma vez que quase não há divulgação ampla acerca do tema.

\section{O STREAMING PARA ALÉM DA INDÚSTRIA MUSICAL}

A indústria dos vídeos e filmes também utiliza a tecnologia streaming. Cabe aqui ressaltar duas das principais plataformas mundiais: YouTube e Netflix.

O YouTube é a plataforma de vídeos online mais utilizada em todo o planeta. A plataforma foi criada em 2005, com intuito de compartilhar vídeos. Em 2006 a plataforma foi comprada pelo Google, por mais de um bilhão de dólares ${ }^{24}$.

Desde então, a o YouTube possui cerca de um bilhão de usuários, quase um terço de todos os usuários da internet. A plataforma afirma ter distribuído US\$ 2 bilhões para os titulares de direitos que optaram por gerar receitas com reivindicações desde que o Content ID foi lançado em $2007^{25}$.

Importante destacar a noção de Content ID. É um sistema utilizado pelos proprietários de direito autoral para identificar e gerenciar o conteúdo deles no YouTube com facilidade, partindo de um banco de dados de arquivos enviados pelos proprietários do conteúdo.

A partir disto, os proprietários podem bloquear a visualização de um vídeo inteiro ou gerar renda com o vídeo ao veicular anúncios e, em alguns casos, ao compartilhar a receita com o usuário que fez o envio ou, ainda, rastrear as estatísticas de visualização do vídeo ${ }^{26}$.

Caso haja violação dos direitos autorais, o proprietário pode reivindicar o Content ID, de forma que pode exigir a remoção do vídeo, respeitando o $\mathrm{DMCA}^{27}$.

A plataforma também se envolveu em uma discussão acerca da existência de execução pública. Em decisão de novembro de 2016, foi determinado que a execução pública só se daria nos casos de transmissão ao vivo dentro da plataforma. Nestes casos, deve-se pagar ao ECAD o valor de $1 \%$ em cima do que for arrecadado com a publicidade dos vídeos $^{28}$.

\footnotetext{
${ }^{24}$ CARPANEZ, Juliana. GOOGLE COMPRA SITE YOUTUBE POR US\$ 1,65 BILHÃO: Apesar de já ter seu próprio serviço de exibição de vídeos, a página do Google não conquistou a mesma popularidade do YouTube. 2006. Disponível em: <http://g1.globo.com/Noticias/Tecnologia/0,,AA1304481-6174,00.html>. Acesso em: 09 jul. 2017.

${ }^{25}$ Informações disponíveis no site da plataforma.

${ }^{26}$ Disponível em https://support.google.com/youtube/answer/2797370?hl=pt-BR

${ }^{27}$ Disponível em https://support.google.com/youtube/answer/2814000?hl=pt-BR\&ref_topic=2778545

${ }^{28}$ BRASIL. Tribunal de Justiça do Estado do Rio de Janeiro. Ação cível no 0116365-13.2015.8.19.0001. Rio de Janeiro, RJ, 22 de novembro de 2016.
} 
A Netflix, por sua vez, é conhecida por ser uma das mais importantes plataformas de filmes, seriados e documentários em todo o mundo. Está disponível em 190 países e possui mais de 100 milhões de usuários no planeta.

Para o licenciamento das obras, a plataforma realiza parcerias com os provedores de conteúdo para licenciar direitos de transmissão, além do conteúdo original, produzido pela empresa $^{29}$. Para um determinado filme ou seriado se manter no catálogo, a plataforma analisa a quantidade de visualizações e o valor do contrato. Por exemplo, quanto mais premiado e com artistas de sucesso, mais caro será o valor da licença.

Uma das grandes críticas acerca da plataforma da Netflix diz respeito a disparidade dos acervos de diversos países. Por exemplo, os filmes disponibilizados nos Estados Unidos são mais diversificados que no acervo brasileiro. Este fato se dá pelo fato de muitos detentores de conteúdo não verem retorno financeiro na distribuição para além de determinada região, principalmente quando há mais de um detentor do conteúdo envolvido ${ }^{30}$.

O próprio CEO da empresa afirmou que possui interesse na unificação do catálogo. Isto seria uma alternativa para evitar a pirataria dentro da própria plataforma, uma vez que muitos usuários utilizam das chamadas redes VPN para alterar o IP do aparelho e acessar o catálogo de outros países.

Apesar dos esforços da Netflix, os grandes estúdios não possuem interesse nesta unificação, o que impossibilita qualquer reação por parte da empresa, uma vez que ela depende dos contratos para distribuir o conteúdo.

\section{CONSIDERAÇÕES FINAIS}

A tecnologia do streaming vem dominando o ambiente digital. Apesar de ser seu principal foco, não é apenas a indústria fonográfica que se utiliza desta inovação.

As plataformas surgem para tentar controlar o sistema de pirataria, tão difundido nas últimas décadas. As pessoas têm deixado de consumir produtos sem licença para se tornarem usuários de programas como a Netflix e o Spotify.

Entretanto, apesar de ser uma tecnologia em plena expansão, ainda há pontos controversos.

\footnotetext{
${ }^{29}$ Disponível em https://help.netflix.com/pt/node/4976

${ }^{30}$ Disponível em https://help.netflix.com/pt/node/4976
} 
As grandes gravadoras e estúdios ainda detém um grande poder de decisão acerca do licenciamento das obras. As plataformas se veem reféns de um sistema que pouco permite flexibilidade na hora de contratar os direitos para distribuição de uma música ou vídeo.

Os artistas também acabam sofrendo com isto. Como a cantora Taylor Swift expôs ao retirar seu catálogo do ar, não há uma justa remuneração. Ademais, as plataformas acabam não publicizando a distribuição referente aos valores a título de direitos autorais.

No Brasil a situação se agrava, pois, o sistema de gestão coletiva acaba retendo ganhos que viriam a ser dos artistas e produtores de conteúdo. O ECAD acaba aferindo valores altos em cima deste sistema de dupla camada.

Ainda há um percurso longo a ser percorrido no que diz respeito à tecnologia do streaming e a distribuição dos direitos autorais. Há que se pensar em um novo sistema, pensando não apenas a nível nacional, mas quem sabe em cooperação com outros países, afinal, o ambiente digital não possui barreiras territoriais.

\section{REFERÊNCIAS}

ARENHART, Gabriela. Gestão Coletiva de Direitos Autorais e a Necessidade de Supervisão Estatal. Publicado em: 25 jul. 2014. Disponível em: http://www.gedai.com.br/?q=pt-br/content/gest\%C3\%A3o-coletiva-de-direitos-autorais-enecessidade-de-supervis\%C3\%A3o-estatal>.

ASCENSÃO, José de Oliveira. Direito Autoral. Rio de Janeiro: Renovar, 1997. p. 620

BITTAR, Carlos Alberto. Contornos atuais do Direito do Autor. São Paulo: Revista dos Tribunais, 1999.

BRASIL. Superior Tribunal de Justiça. Recurso Especial no 1.559.264. Brasília, DF, 15 fev. 2017.

Tribunal de Justiça do Estado do Rio de Janeiro. Ação cível $\mathbf{n}^{0}$ 011636513.2015.8.19.0001. Rio de Janeiro, RJ, 22 nov. 2016.

- Tribunal de Justiça do Estado do Rio de Janeiro. Apelação Cível no 0174958.45.2009.8.19.0001. Relator: Desembargador Antônio Saldanha Palheiro. Rio de Janeiro, RIO DE JANEIRO, 12 abr. 2011. 
Tribunal de Justiça do Estado do Rio de Janeiro. Recurso Especial $\mathbf{n}^{\mathbf{0}}$ 1.559.264. Relator: Ministro Ricardo Villas Boas Cueva. RIO DE JANEIRO, 21 out. 2015

CARPANEZ, Juliana. GOOGLE COMPRA SITE YOUTUBE POR US\$ 1,65 BILHÃO: Apesar de já ter seu próprio serviço de exibição de vídeos, a página do Google não conquistou a mesma popularidade do YouTube. 2006. Disponível em: <http://g1.globo.com/Noticias/Tecnologia/0,,AA1304481-6174,00.html>. Acesso em: 09 jul. 2017.

FRANCISCO, Pedro Augusto P.; VALENTE, Mariana Giorgetti (Org.). Do rádio ao streaming: ECAD, Direito autoral e música no Brasil. Rio de Janeiro: Beco do Azougue, 2016. 390 p.

PESSERL, Alexandre Ricardo. Estudos comparados sobre Direitos Autorais no Ambiente Digital (Internet): Produto 04 - Soluções Implementadas por empresas. Brasilia: Ministério da Cultura, 2014. p. 22.

REUTERS. Spotify atinge 50 milhões de assinantes pagos: Serviço sueco de streaming de músicas aumenta em $25 \%$ a base de usuários pagantes em menos de seis meses. Disponível em: $\quad<$ http://g1.globo.com/tecnologia/noticia/spotify-atinge-50-milhoes-de-assinantespagos.ghtml>. Publicado em 03 mar. 2017. Acesso em: 04 jul. 2017.

SILVA, Marta Santos. Ouvir uma canção no Spotify vale 0,005€. Mas isso é muito ou pouco?. 2016. Disponível em: <https://eco.pt/2016/11/13/ouvir-uma-cancao-no-spotify-vale0005e-mas-isso-e- muito-ou-pouco/>.

SILVA, Victor Hugo. Do catálogo ao consumo de dados: qual o melhor streaming de música? Tecnologia - iG, São Paulo. 24 mar. 2016. Disponível em: $<$ http://tecnologia.ig.com.br/2016-03-24/do-catalogo-ao-consumo-de-dados-qual-o-melhorstreaming-de-musica.html>. Acesso em: 05 jul. 2017.

WACHOWICZ, Marcos. A gestão coletiva de direitos autorais da obra musical: titularidade originária, supervisão pública e transparência. In: SIMÃO, J.F.; BELTRÃO, S.R. Estudos em Homenagem a José de Oliveira Ascensão - Direito Civil: Estudos Em Homenagem A José De Oliveira Ascensão: Direito Privado. Editora: Atlas. Edição: 1ª 2015.

Word Intellectual Property Organization. Collective Management of Copyright and Related Rights. Disponível em: <http://www.wipo.int/copyright/en/management/>. Acesso em: 19 out. 2016. 